\title{
Uso de um Sistema de Radar Multiestático com Tecnologia UWB para Localizar Intruso em Ambientes Bidimensionais
}

\author{
Josivaldo de S. Araújo ${ }^{1,2}$, Rodrigo M. S. de Oliveira ${ }^{1}$, Carlos Leonidas da S.S. Sobrinho ${ }^{1}$ e Rubem G. \\ Farias $^{1}$
}

\begin{abstract}
Resumo - Este trabalho descreve um sistema de radar multiestático que utiliza tecnologia UWB (Ultra-Wideband) para localizar intruso em um ambiente indoor bidimensional. O sistema foi simulado utilizando como método numérico o método das Diferenças Finitas no Domínio do Tempo (FDTD). Para obter uma alta resolução, o radar opera com pulsos que possuem amplitude espectral máxima em $1 \mathrm{GHz}$ e largura de banda de meia potência de aproximadamente $1 \mathrm{GHz}$. A estimativa de localização é feita pela técnica de otimização Enxame de Partículas, PSO (Particle Swarm Optimization).
\end{abstract}

Palavras-chave - Método FDTD, Método PSO, Radar Multiestático, Tecnologia UWB.

Abstract - This work describes a multistatic radar system which uses UWB technology (Ultra-Wideband) in order to locate intruder in a bidimensional indoor environment. The system was simulated using a numerical method called as a Finite-Difference Time-Domain (FDTD). In order to get a high resolution, the radar operates with pulses which have maximum spectral amplitude in $1 \mathrm{GHz}$ and half power bandwidth of approximately $1 \mathrm{GHz}$. The localization estimative is made by Particle Swarm Optimization (PSO) technique.

KeyWords - FDTD Method, PSO Method, Multistatic Radars, UWB Technology.

\section{INTRODUÇÃO}

Nos últimos anos tem havido um crescimento considerável das atenções dos pesquisadores para o estudo de radares que sejam capazes de detectar e localizar precisamente intrusos, mesmo estes estando posicionados atrás de paredes ou outros objetos comuns. São radares que utilizam pulsos de banda ultra larga e que detectam a presença de intrusos medindo mudanças na resposta do ambiente a um pulso. Esses pulsos são extremamente curtos, o que os torna com largura de banda extremamente grande. Essa característica faz com que o pulso tenha uma maior imunidade a atenuações seletivas de frequiências, as quais são inerentes a ambientes ricos em espalhamento, tornando-os adequados para ambientes indoor. Essa tecnologia de pulso é conhecida como pulsos Ultra Wideband, ou pulsos UWB [1].

\footnotetext{
${ }^{1}$ Universidade Federal do Pará (UFPa), Departamento de Engenharia Elétrica e de Computação, Laboratório de Análises Numéricas em Eletromagnetismo, Rua Augusto Corrêa, n.01, 66075-907, Belém, Pará, Brazil. (josivaldo@lane.ufpa.br, rodrigo@lane.ufpa.br, leonidas@ufpa.br, rgfarias@ufpa.br).

${ }^{1,2}$ Universidade da Amazônia (UNAMA), Centro de Ciências Exatas e Tecnologia, Avenida Alcindo Cacela, 287, 66060-902, Belém, Pará, Brazil. Este trabalho foi parcialmente financiado pela FIDESA (Fundação Instituto para o Desenvolvimento da Amazônia).
}

Pelo fato de os pulsos UWB serem tão curtos, eles também podem utilizar espectros de freqüência bastante amplos, permitindo que os sinais usem baixa energia, o que minimiza a interferência de outras frequiências de rádio como telefones, celulares, GPS, Bluetooth, W-LAN IEEE 802.11, entre outros, através do espalhamento espectral, o que acaba por reduzir os riscos à saúde [2] ficando abaixo da linha normal de ruídos, além de torná-los mais difíceis de detectar.

O método das diferenças finitas no domínio do tempo (FDTD), desenvolvido por Kane Yee [3], quando aplicado na solução das equações de Maxweel, permite a simulação da propagação de ondas eletromagnéticas, no domínio do tempo, em toda região de análise. Por conta disso, o método é adequado para simular a propagação de pulsos UWB pela sua facilidade de uso, robustez e precisão. Para realizar o truncamento do domínio analisado foi utilizada a técnica de UPML (Uniaxial Perfectly Matched Layer) [4], a qual limita a região de estudo, simulando uma câmara anecóica.

Este trabalho tem por objetivo apresentar um sistema que simula um radar multiestático utilizando pulsos de banda ultra larga para estimar a posição de um intruso em um ambiente indoor. Essa estimativa da localização será realizada através da técnica de otimização de enxame de partículas.

\section{PARÂMETROS DO SINAL}

A forma de onda do pulso UWB que o radar utiliza para sondar o ambiente, neste trabalho, é o monociclo gaussiano, dado por (1):

$$
p(t)=-A_{p} \sqrt{\frac{2 e}{\tau^{2}}}\left(t-t_{0}\right) \exp \left[-\frac{\left(t-t_{0}\right)^{2}}{\tau^{2}}\right],
$$

na qual $A_{p}$ é a amplitude máxima do pulso, $e$ é a base do logaritmo Neperiano e $\tau$ estabelece a duração do pulso. $\mathrm{O}$ último parâmetro depende da freqüência de pico $\left(f_{0}\right)$ do espectro definida por (2):

$$
f_{0}=\frac{1}{\pi \sqrt{2}} \frac{1}{\tau}
$$

O parâmetro $t_{0}$ é o instante que corresponde ao centro do pulso. Este parâmetro é escolhido de tal maneira a evitar windowing (efeito Gibbs) causado pela trucagem do pulso. A transformada de Fourier de $p(t)$ é dada por (3). 


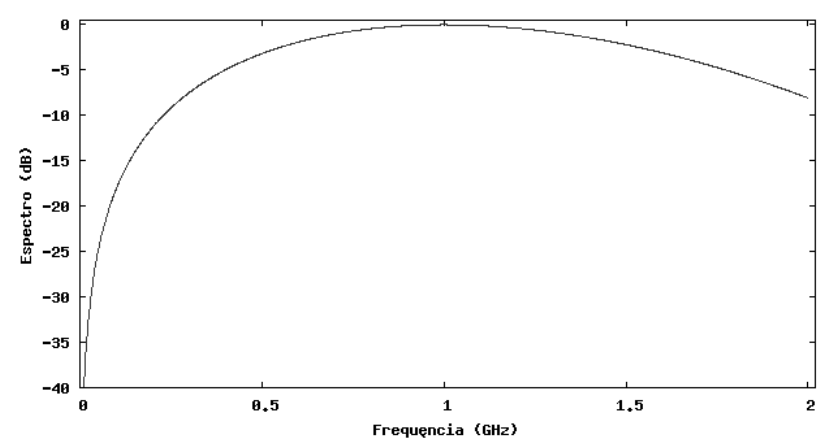

Fig.1. Espectro do Monociclo Gaussiano.

$$
P(f)=A_{p} \tau^{2} \sqrt{\frac{\pi e}{2}} \exp \left[1-(2 \pi f)^{2}\right] \exp \left(-j 2 \pi t_{0} f\right)
$$

O pulso $\mathrm{p}(\mathrm{t})$ tem como entrada os seguintes parâmetros: $A_{p}=1 \mathrm{~V} / \mathrm{m}, \tau \approx 0,255 \mathrm{~ns}\left(f_{0}=1 \mathrm{GHz}\right)$ e $t_{0}=1,8 \mathrm{~ns}$ e uma freqüência que possui amplitude espectral máxima $\left(f_{o}\right)$ de 1GHz, como mostrado na Fig.1.

Para este trabalho, foram utilizadas antenas omnidirecionais. Esse padrão de radiação pode ser justificado pelo fato de ambientes com grande densidade de multipercursos minimizarem os efeitos de acoplamento entre o corpo humano e uma antena muito próxima. Como o ambiente simulado é uma residência, um ambiente denso em multipercursos, a utilização de uma antena omnidirecional parece ser razoável.

\section{DESCRIÇÃO DO AMBIENTE DE SIMULAÇÃO}

Na Fig.2, pode-se observar o ambiente utilizado nas simulações para este trabalho, trata-se de uma residência semelhante à utilizada por Kondylis [5]. Optou-se por essa configuração de residência por representar um ambiente indoor típico.

Para minimizar a dispersão numérica, a discretização do ambiente é feita usando-se células de $15 \mathrm{~mm}$ de aresta $(\Delta \mathrm{x}$ $=\Delta \mathrm{y}=\Delta \mathrm{s}=15 \mathrm{~mm}$ ), que é o valor de um décimo de comprimento de onda da frequiência máxima (3dB) igual a 2 GHz (Fig.2). A malha é uniforme, contendo 790 células na direção $x$ e 754 na direção $y$. Para assegurar estabilidade numérica do método, adota-se o valor de incremento temporal $\Delta$ t calculado por (4), que equivale a $70 \%$ do limite de Courant.

$$
\Delta t=0,7 \frac{\Delta s}{c \sqrt{2}}
$$

na qual $c$ é a velocidade da luz no espaço livre.

Nesse layout as paredes externas possuem espessura de 25,5 cm e as internas de $15 \mathrm{~cm}$ (permissividades relativas entre 2 e 5). Os parâmetros que descrevem a UPML são definidos pelo número de camadas, igual a 10 células, a condutividade máxima, igual a $15 \mathrm{~S} / \mathrm{m}$ e um polinômio de ordem 4 para descrever a condutividade não uniforme das camadas.

As simulações são realizadas usando o método FDTD bidimensional (2D-FDTD). Para antenas de transmissão e recepção, somente a componente $E_{z}$ do campo elétrico (polarização perpendicular relativa ao plano da Fig.2) é considerada (Modo $\mathrm{TM}_{\mathrm{z}}$ ).

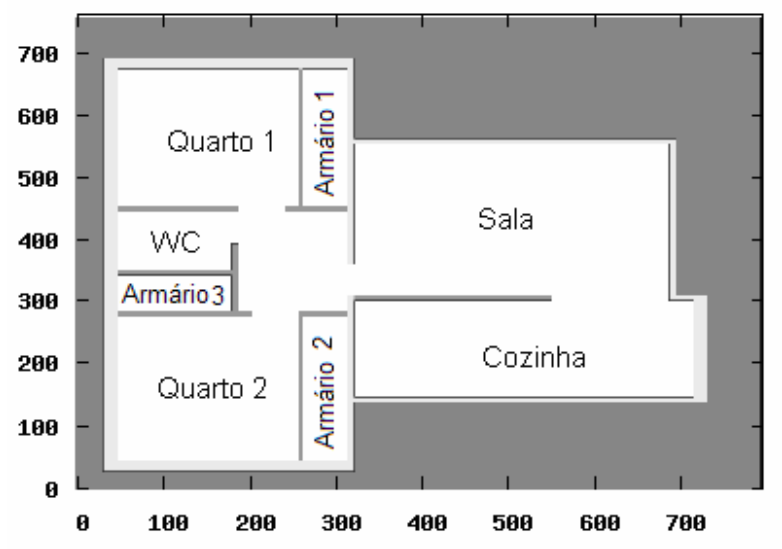

Fig.2. Layout da Residência (eixos em células)

\section{LOCALIZAÇÃO DO ALVO (TÉCNICA PSO)}

O método apresentado neste trabalho para determinar a posição do alvo (um intruso, um ser humano) em relação à origem do sistema de coordenadas, utiliza dois formalismos matemáticos: o método FDTD e o conceito de raio propagante para obter os parâmetros da elipse de localização.

O transmissor e os receptores (três ou mais) formam um radar multiestático. Inicialmente o pulso UWB é transmitido na ausência do alvo, e os dados do campo elétrico $E_{z}$ são obtidos, via FDTD, em cada receptor, e são usados como referência. Depois, o pulso é transmitido com a presença do alvo dentro da residência. O estágio seguinte consiste em obter a diferença entre esses dados (pulso com e sem alvo) seguidos de uma normalização dos registros obtidos e da inclusão de ruído branco gaussiano (AWGN) para simular o ruído ambiente e de equipamentos. Após o processamento desses dados, os parâmetros das elipses (formadas por cada receptor) e do círculo (formado pelo transmissor) são obtidos e um sistema de equações não-lineares, formado pelas equações das elipses e pela equação do círculo, é resolvido para estimar a posição do alvo. Finalmente, é feito o cálculo do erro da estimativa de localização. A estimativa é feita para cada posição dos receptores e do transmissor (o receptor Rx1 é sempre localizado no mesmo ponto do transmissor). Este resultado é a solução final da estimativa da posição do alvo.

A Fig.3 ilustra o caso para um radar com três receptores. No caso de um maior número de receptores, a estimativa da localização do alvo é feita para cada combinação de dois receptores remotos. Para estimativa final adota-se a média entre as soluções dentro de uma região definida pelo desvio padrão e pela média das diversas soluções preliminares. 


\section{A. O Método de Otimização Enxame de Partículas}

O método enxame de partículas (PSO - Particle Swarm Optimization) é um algoritmo relativamente recente de otimização heurística baseado no comportamento gregário do movimento de animais em bando (peixes, pássaros, insetos) em que o comportamento de cada indivíduo é um simultâneo influenciado por fatores próprios e por fatores que resultam do comportamento dos restantes (grupo).

Proposto por Russel Eberhart e James Kennedy [6], em 1995, este método consiste na otimização de uma funçãoobjetivo através da troca de informações entre elementos (partículas) do grupo, resultando em um algoritmo de otimização não determinístico eficiente, robusto e de simples implementação computacional. No entanto, soluções que utilizam somente partículas da vizinhança (caráter mais local), ao invés de todo o grupo, também são encontradas na literatura [7].

O movimento de cada partícula em cada iteração corresponde à soma de três termos distintos: o primeiro, é um termo relativo à inércia da partícula e que traduz o modo com que a partícula vem se movendo (inércia); o segundo, é um termo relativo à atração da partícula ao melhor ponto que já encontrou (memória); e o terceiro termo, é relativo à atração da partícula ao melhor ponto que todo grupo já encontrou (cooperação).

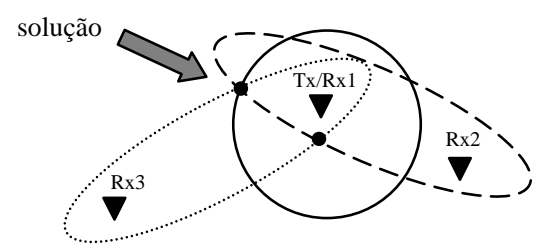

Fig.3. Esquema de um radar multiestático para três receptores

Cada partícula corresponde a uma alternativa de solução para um dado problema de otimização. Dada uma população de $n$ partículas, cada partícula $i$ tem a seguinte composição:

E Um vetor de posição $\mathbf{X}_{\mathbf{i}}$

E Um vetor de velocidade $\mathbf{V}_{\mathbf{i}}$

E Um vetor de memória $\mathbf{b}_{\mathbf{i}}$ da melhor posição encontrada durante a vida da partícula

E Um valor da função-objetivo $F_{i}$ relativo à posição atual $\mathbf{X}_{\mathbf{i}}$

= Um valor de função objetivo fbo $_{i}$ relativo à melhor posição $\mathbf{b}_{\mathbf{i}}$

Num dado instante de tempo t (correspondente a uma dada iteração), uma partícula $i$ muda a sua posição de $\mathbf{X}_{\mathbf{i}}$ para $\mathbf{X}_{\mathbf{i}}^{\text {novo }}$ de acordo com (5).

$$
\mathbf{X}_{\mathbf{i}}^{\text {novo }}=\mathbf{X}_{\mathbf{i}}+\mathbf{V}_{\mathbf{i}}^{\text {novo }}
$$

onde $\mathbf{V}_{\mathbf{i}}^{\text {novo }}$ é a nova velocidade da partícula $i$, ou seja, o vetor representando a mudança de posição da partícula $i$ é dado por (6).

$$
\mathbf{V}_{\mathbf{i}}^{\text {novo }}=\mathbf{V}_{\mathbf{i}}+\mathbf{U} \cdot \mathbf{W} \mathbf{m}_{\mathbf{i}}\left(\mathbf{b}_{\mathbf{i}}-\mathbf{X}_{\mathbf{i}}\right)+\mathbf{U} \cdot \mathbf{W} \mathbf{c}_{\mathbf{i}}\left(\mathbf{b}_{\mathbf{G}}-\mathbf{X}_{\mathbf{i}}\right)
$$

na qual

- $\mathbf{W m}_{\mathrm{i}}$ é uma matriz diagonal de pesos do termo de memória da partícula $i$ em que o elemento $W m_{\mathrm{kk}}^{\mathrm{i}}$ é o peso para a dimensão k do termo de memória;

- $\mathbf{W} \mathbf{c}_{\mathbf{i}}$ é uma matriz diagonal de pesos do termo de cooperação da partícula $i$ em que o elemento $W c^{i}{ }_{k k}$ é o peso para a dimensão $\mathrm{k}$ do termo de cooperação;

- $\mathbf{b}_{\mathrm{G}}$ melhor posição encontrada pelo enxame até o momento;

E $\mathbf{U}=\operatorname{rand()}$ é a variável aleatória com distribuição uniforme no intervalo $(0,1)$;

Os pesos, neste modelo, são definidos inicial e externamente. Suscita-se, de imediato, um problema de definição destes pesos para que a convergência seja conseguida. As velocidades $\mathbf{V}_{\mathbf{i}}$ iniciais, que são sorteadas com cada componente num intervalo $\left[-\mathrm{V}_{\mathrm{k}}{ }^{\mathrm{MAX}}, \mathrm{V}_{\mathrm{k}}{ }^{\mathrm{MAX}}\right]$, para evitar a atribuição de valores excessivos que poderiam causar divergência.

As experiências com o PSO simples, rapidamente mostraram que, se o método parecia ter propriedades interessantes em convergir para a zona do ótimo, apresentava imensas dificuldades em afinar essa convergência, fundamentalmente porque a velocidade das partículas continuava excessiva quando se pretendia que ela se suavizasse para que pudessem ir se aproximando cada vez mais, com maior precisão do ponto ótimo [8].

Rapidamente se compreendeu que seria útil conceber um mecanismo que fosse gradualmente reduzindo a velocidade das partículas, na medida em que estas se aproximassem da solução final. Três mecanismos essenciais foram experimentados:

1) A utilização de uma função decrescente no tempo (ou seja, com o avanço das iterações) afetando o termo de inércia;

2) $\mathrm{O}$ uso de coeficientes redutores do movimento, designados coeficientes de constrição.

3) Simplesmente limitar cada componente de velocidade ao intervalo [- $\left.\mathrm{V}^{\mathrm{MAX}}, \mathrm{V}^{\mathrm{MAX}}\right]$.

Todas as alternativas se mostraram eficientes, sendo que neste trabalho, o terceiro mecanismo foi aplicado.

\section{B. Estimando a posição do alvo com a técnica PSO}

Após as simulações utilizando o método FDTD, podem ser determinados os parâmetros das três curvas que formam o sistema não linear a ser resolvido. No caso ideal, ilustrado pela Fig. 3, as duas elipses e o círculo se interceptam num mesmo ponto, sendo este a estimativa da posição. Todavia, de uma forma geral, isso não ocorre, sendo que, com mais freqüência, a situação ilustrada pela Fig. 4 deve ser solucionada.

Assim, o objetivo do enxame de partículas é localizar um ponto que esteja a uma distância mínima das três curvas simultaneamente, como ilustrado pela Fig. 4. Seguindo esta 
idéia, a função-objetivo utilizada aqui, para o localizador PSO, é dada por (7):

$$
F_{i}=d_{i} C_{\text {min }}+d_{i} E_{\text {min }}^{1}+d_{i} E_{\text {min }}^{2}
$$

na qual

E $F_{i}$ é a avaliação da posição $\mathbf{X i}$;

- $d_{i} C_{\min }$ é a mínima distância de Xi para o círculo ;

- $d_{i} E_{\text {min }}^{1}$ é a mínima distância de $\mathbf{X i}$ para o primeira elipse ;

$=d_{i} E_{\text {min }}^{2}$ é a minima distância de $\mathbf{X i}$ para o Segunda elipse ;

Dessa forma, o PSO age como um minimizador da função-objetivo (7). É importante observar que a situação mostrada pela Fig. 3 também é contemplada pelo algoritmo PSO automaticamente.

Para o presente trabalho, os seguintes pesos foram utilizados para todas as partículas:

$$
\begin{aligned}
& =\mathrm{Wm}=0,0001, \\
& =\mathrm{Wc}=0,0001, \\
& =\mathrm{V}^{\mathrm{MAX}}=0,01 .
\end{aligned}
$$

A obtenção desses valores foi realizada de forma empírica.

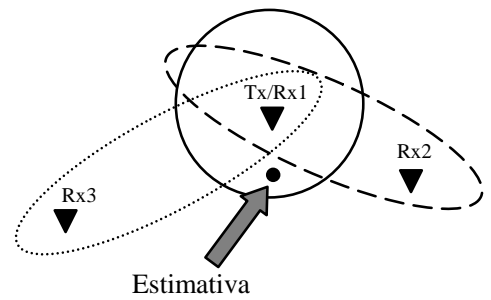

Fig.4. Estimativa do alvo: meta do localizador baseado em PSO.

O ruído AWGN, adicionado à diferença normalizada entre os registros dos receptores obtidos na presença e ausência do alvo, é calculado a partir de duas amostras independentes da variável aleatória $\mathbf{U}=\mathrm{rand}($ ).Uma amostra $\mathbf{R}(\xi)$ do ruído AWGN é fornecida por (8):

$$
\mathbf{R}(\xi)=\sigma_{a} \sqrt{2 \ln \left[1 /\left(1-\mathbf{U}\left(\xi_{j}\right)\right)\right]} \cos \left[2 \pi \mathbf{U}\left(\xi_{k}\right)\right]
$$

na qual $\sigma_{a}=0,02$, para as presentes simulações.

\section{RESULTADOS}

Para todas as simulações realizadas neste trabalho, foi considerado como sendo o alvo, um cilindro com $25.0 \mathrm{~cm}$ de diâmetro - representado nas figuras por um quadrado - e com permissividade elétrica relativa igual a 5.0 e condutividade elétrica igual a $1.43 \mathrm{~S} / \mathrm{m}$. Com relação ao posicionamento dos receptores e do transceptor foram consideradas duas situações: na primeira, o sistema de radar multiestático foi posicionado do lado de fora da residência e na segunda situação, o sistema foi posicionado do lado de dentro da residência.

\section{A. Radar Posicionado Fora da Residência}

Para esta análise o sistema de radar foi posicionado na parte exterior da residência e para todas as situações simuladas, foram considerados três receptores e um transceptor, todos posicionados conforme Figs. 5-9. Os valores de posicionamento e localização são considerados em números de células.

Na situação visualizada na Fig. 5, o alvo foi posicionado no quarto 2 (como descrito na Fig. 2). Os símbolos “ $\square$ ” e “+” representam a posição real e localização estimada (calculada) para o alvo, respectivamente. O centro do alvo é posicionado em $(150,180)$ e o resultado calculado, em relação ao centro do quadrado, foi de $(135,182)$, resultando em um erro de $1,86 \%$, percebe-se com isso, que houve uma localização precisa do intruso.

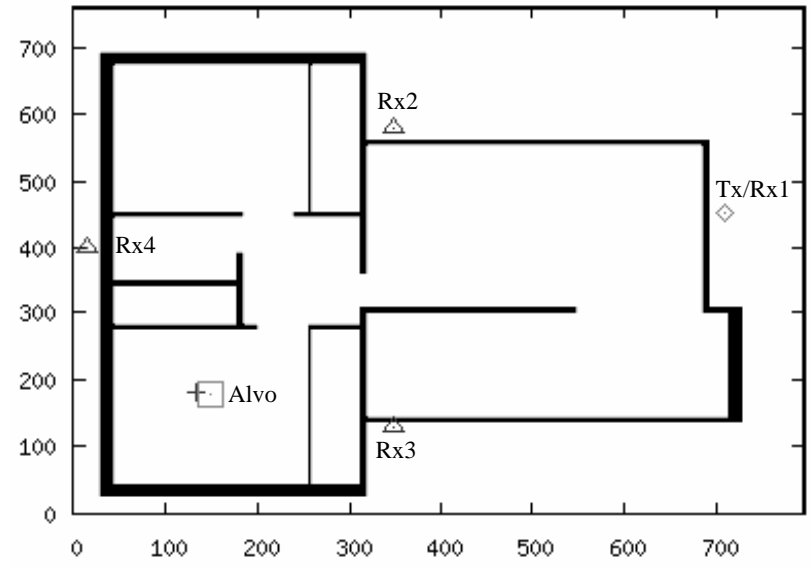

Fig.5. Estimativa de localização de alvo. Posição dos elementos (em número de células): Tx/Rx1 (710,452), Rx2 (350, 580), Rx3 $(350,130)$ e $\operatorname{Rx} 4(15,400)$.

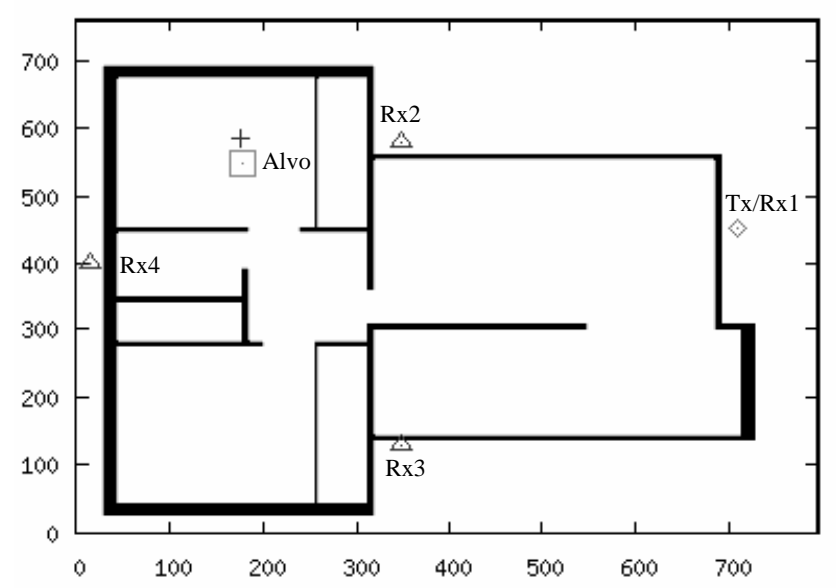

Fig.6. Estimativa de localização de alvo. Posição dos elementos (em número de células): Tx/Rx1(710,452), Rx2 (350, 580), Rx3 $(350,130)$ e $\mathrm{Rx} 4(15,400)$.

Na análise seguinte, o alvo é deslocado para o quarto 1, posição $(180,550)$ e as posições dos receptores e do transceptor são mantidas, Fig. 6. Para esta situação, apesar do sistema não ter localizado o alvo na posição exata, conseguiu localizá-lo no cômodo correto. No entanto, obteve-se uma melhora no resultado, quando se permutou a 
posição do receptor 3 com o transceptor, Fig.7. Para essa configuração a posição calculada foi $(178,562)$, resultando em um erro de $1,48 \%$.

Situações similares foram percebidas conforme 0 deslocamento do alvo, ou seja, em algum momento foi realizada a permuta do transceptor (Tx/Rx1) com algum receptor para que a localização fosse realizada com mais precisão.

Outra importante situação que deve ser observada é quando o alvo está localizado na frente do transceptor, como pode ser observado na Fig.8. Para esta situação o alvo foi posicionado em $(660,452)$ e a posição calculada foi de (703, 496), ou seja, fora da residência, obtendo-se um erro de $7,66 \%$.

Para se obter uma localização satisfatória, também foi necessário permutar o transceptor com o receptor 3, conservando-se as outras posições. A localização calculada se deu na posição $(653,452)$ obtendo um erro de apenas de 0,85\%, como mostrado na Fig. 9.

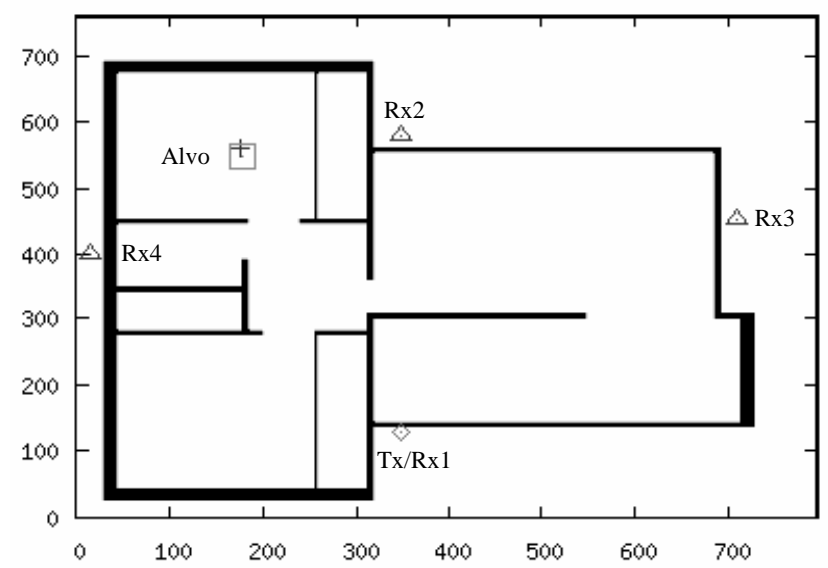

Fig.7. Estimativa de localização de alvo. Posição dos elementos (em número de células): Tx/Rx1(350,130), Rx2 (350, 580), Rx3 $(710,452)$ e $\operatorname{Rx} 4(15,400)$.

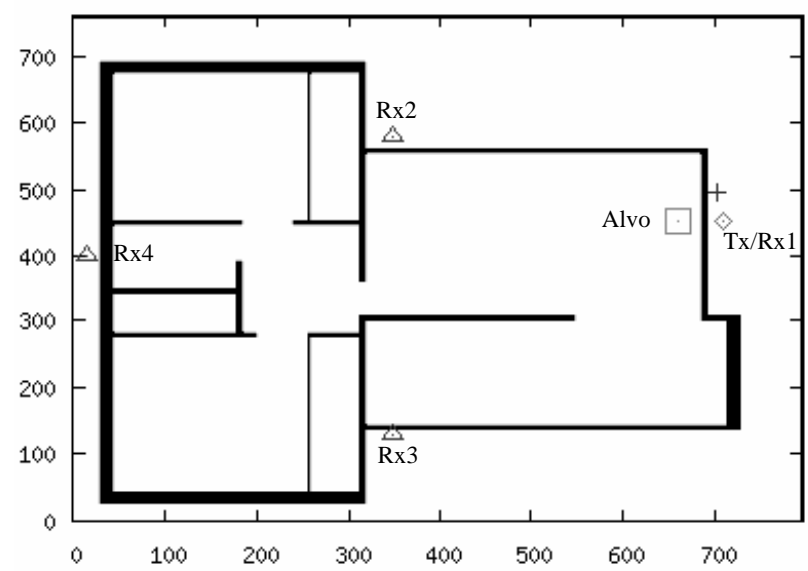

Fig.8. Estimativa de localização de alvo. Posição dos elementos (em número de células): Tx/Rx1(710,452), Rx2 (350, 580), Rx3 $(350,130)$ e Rx4 $(15,400)$.
Com isso, percebe-se que a permuta entre os receptores e o transceptor se faz necessário para que haja uma localização mais satisfatória do alvo.

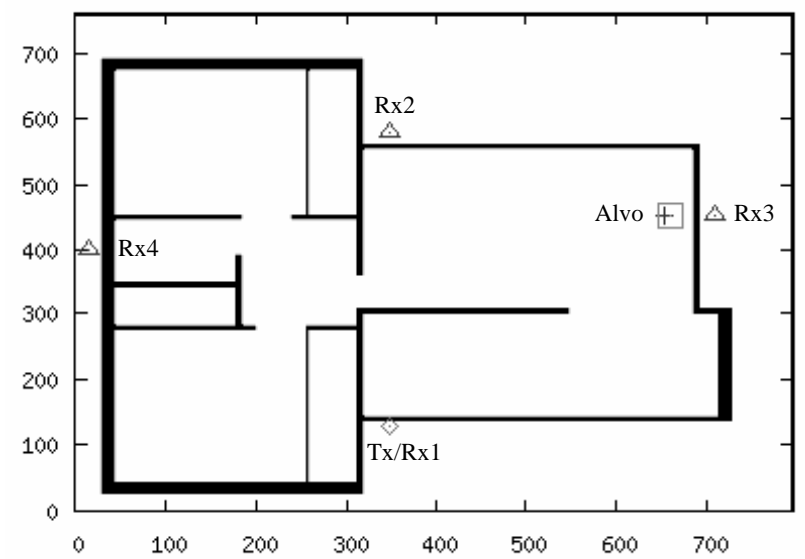

Fig.9. Estimativa de localização de alvo. Posição dos elementos (em número de células): Tx/Rx1(350,130), Rx2 (350, 580), Rx3 $(710,452)$ e $\mathrm{Rx} 4(15,400)$.

\section{B. Radar Posicionado Dentro da Residência}

Na segunda situação o sistema de radar foi posicionado na parte interior da residência e para todas as situações simuladas, também foram considerados três receptores e um transceptor. Os valores de posicionamento e localização são considerados em números de células.

Para a situação visualizada na Fig. 10, o alvo é posicionado no meio do corredor, possuindo o seu centro na posição (250, 350). A posição calculada foi (256, 345.5), ficando o erro em apenas $0,90 \%$.

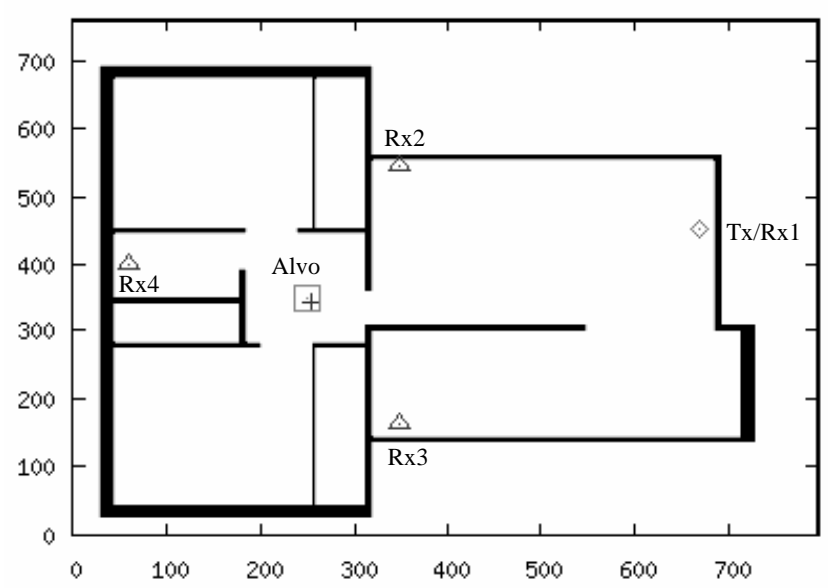

Fig.10. Estimativa de localização de alvo. Posição dos elementos (em número de células): Tx/Rx1(670, 452), Rx2 (350, 545), Rx3 $(350,165)$ e $\mathrm{Rx} 4(60,400)$.

Já na Fig. 11, o alvo é colocado ao lado do transceptor. O centro do alvo está posicionado em $(670,410)$ e o resultado calculado foi $(668.5,423.5)$, tendo um erro de $1,67 \%$, ou seja, o sistema consegue localizar o alvo, mesmo este estando posicionado ao lado do transceptor. 


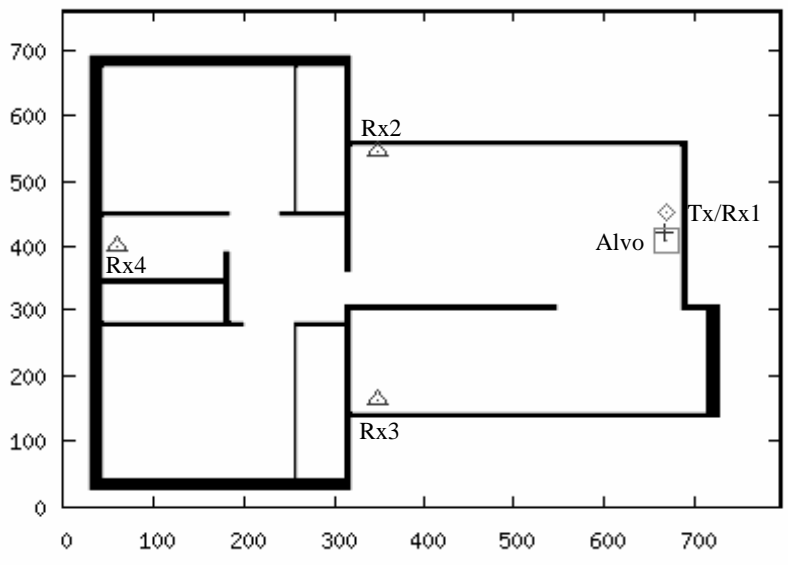

Fig.11. Estimativa de localização de alvo. Posição dos elementos (em número de células): Tx/Rx1(670, 452), Rx2 (350, 545), Rx3 $(350,165)$ e Rx4 $(60,400)$.

Outra simulação considerada foi semelhante a realizada na Fig. 8, onde o alvo é colocado na frente do transceptor, posição (640, 452). Mesmo para esta situação, a localização se mostrou de forma precisa, como observado na Fig.12, onde a localização se deu na posição $(653,456)$, obtendo-se um erro de $1,67 \%$, ou seja, não houve a necessidade de permutar o transceptor com nenhum dos receptores.

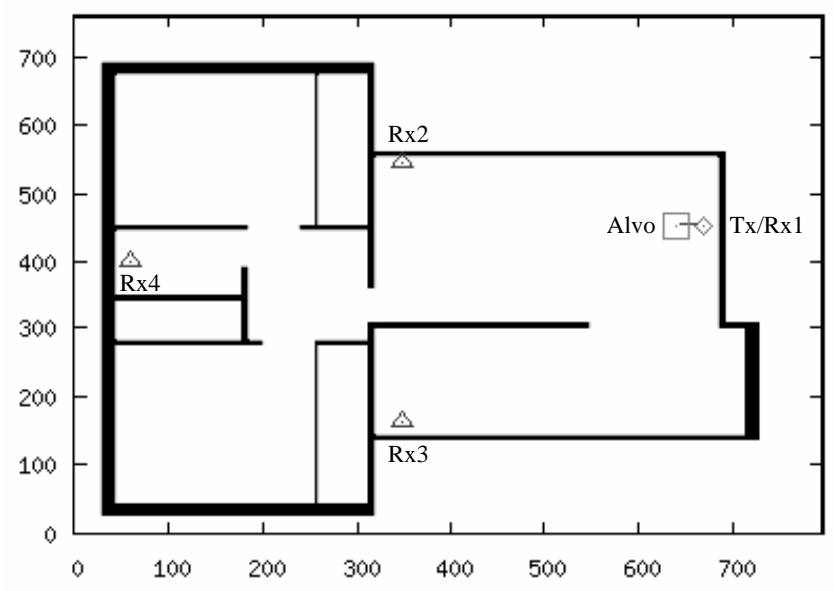

Fig.12. Estimativa de localização de alvo. Posição dos elementos (em número de células): Tx/Rx1(670, 452), Rx2 (350, 545), Rx3 $(350,165)$ e $\operatorname{Rx} 4(60,400)$.

Percebe-se nas simulações que quando o sistema de radar está posicionado na parte interior da residência, não há a necessidade de mudança de posicionamento entre o transceptor e os receptores, pois o pulso UWB emitido percorre menos obstáculos (neste caso a onda eletromagnética não precisa atravessar as paredes externas da residência) o que resulta em uma melhor localização do alvo e consequentemente, um desempenho mais satisfatório do sistema. Isso pôde ser observado, nas Fig. 11 e Fig. 12, quando o alvo é colocado ao lado e na frente do transceptor, respectivamente.

\section{CONCLUSÃO}

Neste trabalho, foi utilizado um sistema de radar multiestático que opera com pulsos UWB, que tem como objetivo a localização de um intruso em ambientes indoor bidimensionais. O sistema foi simulado utilizando o método FDTD, devido a sua facilidade de uso. Os resultados demonstram que a utilização interna do sistema de radar se mostrou mais eficiente e que, apesar da simulação possibilitar um sistema com até sete receptores, os resultados foram satisfatórios com apenas quatro desses receptores. Dessa forma, pode-se concluir que em um sistema de localização por radar multiestático indoor não é o aumento da quantidade de receptores que define o bom funcionamento de um sistema, ou seja, a máxima de “quanto mais melhor" não é aplicada para este caso, já que se obteve excelentes resultados utilizando apenas quatro receptores. Determinar o número ótimo de receptores para cada situação, bem como os seus posicionamentos, é fundamental, pois melhora o desempenho do sistema, permitindo uma localização mais rápida e eficiente do intruso.

\section{REFERENCIAS}

[1] Taylor, J. D., Ultra-Wideband Radar Technology, Florida: CRC Press LLC, 2001.

[2] Welch, T. B., Mulsselman, R. L., Emessiene, B. A., Gift, P. D., et al, "The effects of the human body on UWB signal propagation in an indoor environment”, IEEE Journal on Selected Areas in Commun, vol.20, N ${ }^{\circ}$ 9, December, 2002.

[3] Yee, K.S., "Numerical solution of initial boundary value problems involving Maxwell's equations in isotropic media,"IEEE Trans. Antennas Propagat., vol. AP-14, pp. 302307, May 1966.

[4] Gedney, S. D., “An Anisotropic Perfectly Matched Layer Absorbing Medium for the Truncation of FDTD Lattices", IEEE Trans. Antennas Propagat., vol. AP-44, No. 12, pp. 1630-1639, Dezembro, 1996.

[5] Kondylis, G. D., On indoor wireless channel characterization and design of interference aware medium access control protocols for packet network, University of California, Los Angeles, PhD. Thesis, 2000.

[6] Kennedy, J., and Eberhart, R. C., "Particle Swarm Optimization", Proc. Of IEEE International Conference on Neural Networks (ICNN), Vol. IV, pp.1942-1948, Perth, Australia, 1995.

[7] Chen, J., Quin, Z., Li, Y., Lu, J., "Particle Swarm Optimization with Local Search", International Conference on Neural Network and Brain, 2005”, Vol. 1, pp. 481-484, Oct. 2005.

[8] Miranda, V., "Computação Evolucionária Fenotípica”, Notas de aulas, versão 2.0, Universidade do Porto, Porto, Março, 2005. 